\title{
WORKER PERFORMANCE AND VENTILATION IN A CALL CENTER: ANALYSES OF WORK PERFORMANCE DATA FOR REGISTERED NURSES
}

\author{
CC Federspiel $^{1}$, WJ Fisk ${ }^{4}$, PN Price ${ }^{4}$, G Liu $^{2}$, D Faulkner ${ }^{4}$, \\ DL Dibartolomeo ${ }^{4}$, DP Sullivan ${ }^{4}$, M Lahiff $^{3}$ \\ ${ }^{1}$ Center for the Built Environment \\ University of California \\ Berkeley, CA, 94720-1839, USA \\ ${ }^{2}$ Department of Electrical Engineering \\ University of California \\ Berkeley, CA, 94720, USA \\ ${ }^{3}$ School of Public Health \\ Division of Biostatistics \\ University of California \\ Berkeley, CA, 94720, USA \\ ${ }^{4}$ Indoor Environment Department \\ Environmental Energy Technologies Division \\ Lawrence Berkeley National Laboratory \\ Berkeley, CA, USA
}

May 2004

This work was supported by the Center for the Built Environment at U.C. Berkeley and by the Assistant Secretary for Energy Efficiency and Renewable Energy, Building Technology Program, of the U.S. Department of Energy (DOE) under contract No. DE-AC03-76SF00098. 


\section{WORKER PERFORMANCE AND VENTILATION IN A CALL CENTER: ANALYSES OF WORK PERFORMANCE DATA FOR REGISTERED NURSES}

CC Federspiel ${ }^{1}$, WJ Fisk ${ }^{4}$, , PN Price ${ }^{4}$, G Liu $^{2}$, D Faulkner ${ }^{4}$, DL Dibartolomeo ${ }^{4}$, DP Sullivan ${ }^{4}$, M Lahiff $^{3}$

${ }^{1}$ Center for the Built Environment, University of California, Berkeley, CA, 94720-1839, USA, 510-643-5571 (FAX), cliff_f@uclink.berkeley.edu

${ }^{2}$ Department of Electrical Engineering, University of California, Berkeley, CA, 94720, USA

${ }^{3}$ School of Public Health, Div. of Biostatistics, University of California, Berkeley, CA, 94720, USA

${ }^{4}$ Indoor Environment Dept., Lawrence Berkeley National Laboratory, Berkeley, CA, USA 


\begin{abstract}
We investigated the relationship between ventilation rates and individual work performance in a call center, and controlled for other factors of the indoor environment. We randomized the position of the outdoor air control dampers, and measured ventilation rate, differential (indoor minus outdoor) carbon dioxide $\left(\Delta \mathrm{CO}_{2}\right)$ concentration, supply air velocity, temperature, humidity, occupant density, degree of under-staffing, shift length, time of day, and time required to complete two different work performance tasks (talking with clients and post-talk wrap-up to process information). $\Delta \mathrm{CO}_{2}$ concentrations ranged from 13 to $611 \mathrm{ppm}$. We used multi-variable regression to model the association between the predictors and the responses. We found that agents performed talk tasks fastest when the ventilation rate was highest, but that the relationship between talk performance and ventilation was not strong or monotonic. We did not find a statistically significant association between wrap-up performance and ventilation rate. Agents were slower at the wrap-up task when the temperature was high $\left(>25.4{ }^{\circ} \mathrm{C}\right)$. Agents were slower at wrap-up during long shifts and when the call center was under-staffed.
\end{abstract}

\title{
INDEX TERMS
}

Ventilation rates, Productivity, Offices, Worker performance, Carbon dioxide

\section{INTRODUCTION}

Among building designers, operators, and code authorities, there is a growing interest in the impact of indoor air quality on human performance in commercial buildings. Knowledge about how indoor air quality affects work performance could be used to "optimize" the design and operation of commercial buildings. It could also be used to specify minimum ventilation rates in building codes and standards.

There is a large body of research results on the effects of the indoor environment on sick building syndrome (SBS) symptoms. The amount of ventilation air in particular has received considerable attention because low levels of ventilation have been suspected of causing a variety of health problems. Prior research suggests that performance (e.g., speed or accuracy) of cognitive work can be affected by indoor thermal conditions (Wyon 1993, 1996a, 1996b, Seppanen et al 2003). In previous studies, increased ventilation rates and reduced indoor carbon dioxide concentrations have been associated with improvements in health at work (Seppanen et al., 1999). Field intervention studies have been used by Jaakkola et al. (1990), Jaakkola et al. (1991), Wyon (1992), and Menzies et al., (1993) to test for a relationship between ventilation rate and the frequency and intensity of sick building syndrome symptoms. Jaakkola et al. (1991) showed an increase in SBS symptoms when the amount of outdoor air was reduced. Seppanen et al. (1999) found nearly consistent decreases in SBS symptoms when ventilation was increased within the 0 to 10 liters per second per person range. In addition, some studies reviewed found that increasing ventilation rates above 10 liters per second per person was associated with decreases in SBS symptoms.

Until recently it has been very difficult to measure real-world work performance in a way that is compatible with a scientific study. Most work performance is "measured" with annual performance reviews. These reviews are highly subjective, and do not occur frequently enough for use in an intervention study. As a result, many studies of the impact of indoor air quality on work performance have used performance on tests or tasks designed by the researchers to 
emulate or measure real work performance, but that are not part of any real job function. For example, Nunes et al. (1993) administered acomputerized neurobehavioral tests of sustained visual attention and a sick building symptoms (SBS) survey in a field study. Those workers who reported building-related health symptoms had a 7\% slower response $(\mathrm{p}<0.001)$ and had 30\% higher error rates in a symbol-digit substitution test of speed and coding ability. In a study of 35 Norwegian classrooms, higher concentrations of $\mathrm{CO}_{2}$, which indicate lower rates of outside air ventilation per person, were associated with poorer performance $(p<0.01)$ in computerized tests of reaction time (Myhrvold et al., 1996); however, the percentage change in performance was not specified. Wargocki et al. (2000) report the results of an experiment in a laboratory designed to emulate office work. The laboratory looked like an office, and subjects performed tasks designed to emulate office work. They found that work performance was worsened by the presence of old carpet taken from a complaint building, which when present was behind a partition so that subjects were not aware that it was there. Bakó-Biró et al. (2002) describe the results of a very similar laboratory experiment designed to simulate the effect of IAQ on office work. Female subjects were exposed to two conditions, one with new personal computers (PCs), the other without PCs. The results showed that the new computers were a significant perceived pollution load and that the performance on tasks designed to simulate office work was worse when the computers were present.

There are fewer studies that report the relationship between indoor environmental factors and real work performance. Kroner et al. (1992) used the time taken to resolve an insurance claim as the dependent variable in a study of the productivity effects of moving to a new building, and later, of disabling some of the advanced technology used by office workers to control their own environment in the new building. Niemelä et al. (2002) performed a cross-sectional study in a call center with a small group of subjects which showed that temperatures above $25{ }^{\circ} \mathrm{C}$ were associated with operator performance reduction of 5-7\%. Milton et al. (2000) showed an association between reduced increased air ventilation rates and reduced absenteeism with a study of 40 buildings. In a follow-up study involving an intervention measure that altered the ventilation rate in two buildings, Myatt et al. (2002) were not able to establish the same association. The differential carbon dioxide concentrations observed by Myatt et al. (2002) were much lower that the upper limit recommended by codes and standards. Wargocki et al. (2003) performed a field intervention in a call center in which the ventilation rate was changed between two levels ( $2.5 \mathrm{l} / \mathrm{s} /$ person vs $25 \mathrm{l} / \mathrm{s} /$ person), and filter cleanliness was changed (new filter vs used filter). The results showed that call center agents worked faster at increased ventilation rates when a new particle filter was utilized, but with an old filter present increased ventilation was associated with slower work performance. Tham et al. (2003) performed a field intervention in a call center in which the ventilation rate was changed between two levels $(4.5 \mathrm{l} / \mathrm{s} /$ person vs 12 $1 / \mathrm{s} /$ person) and indoor temperature was changed between two levels $\left(22.5^{\circ} \mathrm{C}\right.$ vs $\left.24.5^{\circ} \mathrm{C}\right)$. The results showed that decreased temperature was associated with increased work speed when the ventilation rate was low and increased ventilation rate was associated with increased work speed when the temperature was high. At low temperature, the association between ventilation rate and performance was not statistically significant. Likewise, at high ventilation, the association between temperature and performance was not statistically significant. 
This paper describes a study of the relationships between real world work performance in a call center and indoor environmental factors. Preliminary findings from this study were presented by Federspiel et al. (2002) and Fisk et al. (2002).

\section{BUILDING DESCRIPTION AND PERFORMANCE METRICS}

The study building is a call-center operated by a health maintenance organization located in northern California. The building, constructed in 1998, has two floors, a total floor area of 4,600

$\mathrm{m}^{2}\left(50,000 \mathrm{ft}^{2}\right)$, sealed windows, carpeted floors, concrete ceilings, and walls of glass and concrete. Workstations are predominately located within cubicles that house one to four workers. Each call center worker has a computer and telephone with a headset. The appearance of the workspace is pleasant and the maximum worker density in the building of 6.3 persons per $100 \mathrm{~m}^{2}\left(1076 \mathrm{ft}^{2}\right)$ is typical of offices

The call center was heated, cooled, and ventilated by four variable air volume (VAV) air handling units (AHUs) that modulated the flow of cool or warm air to maintain indoor air temperatures in the desired range. One of these AHUs did not serve spaces served by agents while they handled calls, so data from that unit were not included in the individual performance analysis. Each AHU had an air-side economizer control system that modulated the flow rate of outside air, above a minimum rate established by the building code, with the goal of minimizing costs for cooling; however, to prevent unplanned changes in outside air supply the economizer controls were deactivated during most experimental periods.

Two kinds of agents work in the call center, registered nurses (RNs) who provide medical advice and tele-service representatives (TSRs) who screen calls and schedule appointments. In this paper we only consider performance data related to the RNs. We did not analyze the performance data from TSRs because the TSRs spent much less time on the wrap-up task than RNs. In many cases the wrap-up times for TRSs were zero. The maximum number of RNs and TSRs in the building during this study was 119 and 173, respectively.

Agents perform two discrete tasks for each call that they handle. The first is talking to the client on the telephone. This task is referred to as the talk task. The second task is called the wrap-up task. This task involves data entry after the agent has finished the talk task. Agents are free to work at their own pace during the wrap-up task. When wrap-up is complete the agent signals the automated call distribution (ACD) system that she is ready to accept another call. We expected environmental stressors to have a bigger impact on the wrap-up task than on the talk task because agents are free to work at their own pace during wrap up; they are not constrained by their interaction with a client.

We analyzed performance data from two kinds of reports: 1) those with the average talk time and average wrap-up time of each agent averaged over a work shift, and 2) the those with the average handle time (talk time plus wrap-up time) averaged for all agents on call in 30-minute, nonoverlapping intervals. The individual performance reports allowed us to control for variations in average individual performance and to control for and model spatial variations in exposure, but did not give good time resolution. The group performance reports provided good time resolution, but no spatial resolution and no ability to control for average individual performance variation. 
Agents sign in to the ACD system with a unique identification number. Individual performance data were averaged over the length of the shift that each agent worked each day. Agents sign out of the ACD system when they finish a shift. We used reports with sign-in and sign-out times for each agent each day to determine the length of each agent's shift. Work shifts varied from 0.5 to 15 hours.

The ACD system records a metric called NETS. NETS is the number of agents scheduled to be on call minus the number needed to keep the client waiting time in the queue equal to a target value. When NETS is negative the call center is under-staffed.

The agents worked in organizational units called neighborhoods. We used the locations of the neighborhoods to associate sensor data such as temperature, humidity, outdoor airflow rate, and $\Delta \mathrm{CO}_{2}$ concentration with individual agents. Some measurements such as outdoor airflow rate were made at each AHU. We determined which neighborhoods were served by which AHU in order to associate sensor data from the AHUs with individual agents.

\section{METHODS}

The intervention method used in this study involved changing the position of the dampers that regulate the amount of outside air entering each AHU. We did not alter any other settings of the controls, nor did we change any of the equipment such as filters. Air filters were changed by the maintenance staff during July 2000. The interventions started on July 28, 2000 and lasted until October 24, 2000. The agents did not know we were changing the outside airflow rates.

We changed the outside air damper positions automatically with equipment that we added to each AHU. We attempted to have randomized daily changes during the middle of the study with weekly settings at the beginning and end of the study. However, the equipment failed during a few periods. Table 1 shows the damper settings that were actually achieved. The damper settings corresponded approximately to four ventilation rates: code-minimum ventilation, $2 \mathrm{X}$ code, $4 \mathrm{X}$ code, and $8 \mathrm{X}$ code. We did not use these settings as predictor categories explicitly. Instead we measured ventilation rate at each AHU using the $\mathrm{CO}_{2}$ mass balance method described by Drees et al. (1992).

Table 1: Ventilation control schedule. $\mathrm{L}, \mathrm{M}$, and $\mathrm{H}$ refer to fixed damper positions for low, medium, and high ventilation rates. $E$ refers to control of ventilation rates by the economizer.

\begin{tabular}{|l|l|l|l|l|l|l|l|l|l|l|l|l|l|}
\hline \multirow{2}{*}{ Day } & \multicolumn{10}{|l|}{$\mathbf{2}$} \\
\cline { 2 - 15 } & $\mathbf{1}$ & $\mathbf{2}$ & $\mathbf{3}$ & $\mathbf{4}$ & $\mathbf{5}$ & $\mathbf{6}$ & $\mathbf{7}$ & $\mathbf{8}$ & $\mathbf{9}$ & $\mathbf{1 0}$ & $\mathbf{1 1}$ & $\mathbf{1 2}$ & $\mathbf{1 3}$ \\
\hline F & L & H & E & H & L & E & M & M & H & M & E & E & E \\
\hline Sa & L & H & L & E & H & M & M & M & M & L & E & E & E \\
\hline Su & L & H & H & L & M & L & M & M & E & M & E & E & E \\
\hline M & L & H & E & H & L & M & M & M & M & H & E & E & L \\
\hline Tu & L & H & M & E & H & L & M & L & H & E & H & H & E \\
\hline W & L & H & H & L & E & H & M & M & L & E & H & E & -- \\
\hline Th & L & H & M & H & M & E & M & L & E & E & H & E & -- \\
\hline
\end{tabular}


We used the difference between the $\mathrm{CO}_{2}$ concentration in the return air and the outside air as a ventilation metric, which we refer to as $\Delta \mathrm{CO}_{2}$. The values of $\Delta \mathrm{CO}_{2}$ are an imperfect surrogate for outside air supply rates per person. $\Delta \mathrm{CO}_{2}$ is also a measure of the degree of control of occupantgenerated air pollutants via outside air ventilation.

Supply airflow rates were monitored using one to three pitot tubes in each supply duct. The locations of the pitot tubes were determined based on measurements from eight points in the cross-section of each duct. Data from the pitot tubes were recorded once per minute. Air temperature and humidity were measured approximately one meter above floor level throughout the spaces occupied by the study population. Temperatures were logged every one minute at 25 indoor locations and relative humidities were logged every five or 15 minutes at 11 indoor locations.

The call center operates 24 hours per day, 7 days per week. We discarded data when few workers were present, only including data from shifts that started after 6am and ended before 10pm (individual performance analysis) of from 7:30am to 6 $\mathrm{pm}$ (group performance analysis), Monday through Friday. Prior to 6am and after 10pm there were no TSRs on call, so RNs performed dual functions. Data from a holiday (Labor Day) were excluded. Data from the first two weeks and from one week in the middle of the study were excluded because of changes made to the ACD system software. For the individual analysis, we removed data from agents who worked less than 20 shifts during the study period. We removed data where either the predictors or the performance metrics were clearly outside a reasonable range (e.g., calls lasting hours or negative values of $\Delta \mathrm{CO}_{2}$ ). We eliminated performance data from agents who were managers of a group. The software that runs the ACD system was upgraded 9 days before the start of the study and on the $58^{\text {th }}$ day of the study (a Friday evening). We observed a transient in the daily-average wrapup times during the first two weeks of the study, so we discarded the first day (a Friday) and the following two weeks of data. We found that the transient in the daily-average wrap-up times was shorter after the second software upgrade, so we only discarded one week of data after that event. We included an indicator variable to account for the performance difference after the second software upgrade. We included indicator variables for time of week. Each of these indicators spanned a two-hour time period, so there were a total of 40 .

We used multi-variable regression to estimate the relationship between environmental factors and ventilation. For the group performance data we constructed a time series model to account for time correlation. We used the observed serial correlation (or, rather, the observed lagged covariance) to estimate the variance-covariance matrix of the residuals, assuming the covariance to be identically zero for time lags exceeding six hours. Following a standard approach for regression in which the residuals have an off-diagonal variance-covariance matrix (e.g. see Box et al. (1994), p.363 or Gelman et al. (1995), p. 257), we then performed a linear regression that used the same explanatory variables but adjusted for the temporal correlation of the residuals. We did not attempt to include time correlation in the individual performance analysis because the shifts lengths were comparable to the length of the observed time correlation in the group analysis.

All results in this paper are for models predicting the logarithm of the talk time or handle time as a linear function of predictors. The nonlinear transformation (logarithm) makes the model 
multiplicative. The response variable (talk time or wrap-up time) is the product of the exponentials of the predictors. The logic behind a multiplicative model is that stressors should have a proportional impact on the response because it is a time variable. A stressor that causes a one minute call to become a two minute call should make a five minute call become a ten minute call, not a six minute call. An additive model would make sense if a stressor normally caused an interruption just once per call. We tried additive models (no logarithmic transformation) and found that the statistical performance was about the same as the multiplicative model. We report the results of the multiplicative models because we believe they are a better representation of how the predictors influence the responses.

We had no direct measurements of noise, call content, caller cooperation, worker motivation, or other factors that are expected to directly influence agent performance, but we did have explanatory variables that serve as proxies for these parameters:

1. Noise and level of activity are related to the number of agents working at a given time, so we included the number of agents on call as one of our explanatory variables.

2. Callers' cooperation, workers' motivation and call content were all expected to be related to queue length, so we included NETS as a predictor variable .

3. Call content was expected to vary by time of week, so we included time-of-week indicator variables in the regression.

4. Indoor air pollutant levels were not directly measured with useful frequency, but indoor and outdoor carbon dioxide were measured periodically. $\mathrm{CO}_{2}$ concentration never reached levels at which it would directly affect performance. However, the difference between the indoor and outdoor concentration $\left(\Delta \mathrm{CO}_{2}\right)$ is a proxy for occupant-generated pollution. The difference between indoor and outdoor $\mathrm{CO}_{2}$ concentrations, $\Delta \mathrm{CO}_{2}$, should be correlated with the indoor concentration of any pollutant emitted indoors at a rate that is approximately proportional to the number of people in the building. Examples of such pollutants are body odors, perfumes, dust stirred up by activity, and emissions from equipment used by occupants such as computers and copy machines.

Since all individual performance data were averaged over a work shift lasting hours, we used the average of the dependent variables over the interval of each shift as predictor variables. We did not try to account for variability of the environmental factors during each shift as potential dependent variables in our models.

For the individual performance analysis, we tried models with linear and categorical terms for $\Delta \mathrm{CO}_{2}$, a linear $\Delta \mathrm{CO}_{2}$ term multiplied by shift length, linear, inverse linear, and categorical terms for ventilation rate, ventilation rate multiplied by shift length, quadratic and categorical terms for temperature, quadratic terms for enthalpy, a linear term for occupant density, quadratic and categorical terms for NETS, and linear and categorical terms for shift length. The following results are for a model with a categorical term for either $\Delta \mathrm{CO}_{2}$ or ventilation rate, a categorical temperature term, a linear occupant density term, a categorical NETS term, and a categorical shift length term.

\section{RESULTS}

Individual Performance 
Descriptive statistics for the explanatory variables are shown in Table 2 . The ventilation rate distribution has three modes that correspond to low, medium, and high damper settings. The temperature distribution has a long high-temperature tail. The relative humidity has a long lowhumidity tail. The number of occupants includes TSRs because occupant density is a proxy for auditory and visual distractions. The distribution of shift length has four modes corresponding to $4,5,6$, and 8 hour shifts. Below the 4-hour mode there is a long tail of short shifts.

Table 2: Descriptive statistics of explanatory variables.

\begin{tabular}{|l|l|l|l|l|l|l|l|}
\hline & $\Delta \mathrm{CO}_{2}$ & Vent & Temp & RH & Occ. & NETS & Shift \\
\hline min & $13 \mathrm{ppm}$ & $0.261 / \mathrm{s}^{2} \mathrm{~m}^{2}$ & $21.0 \mathrm{C}$ & $20.2 \%$ & 66.6 & -11 & $0.48 \mathrm{hrs}$ \\
\hline med & 243 & 1.38 & 23.0 & 42.5 & 156.3 & 1.8 & 6.4 \\
\hline mean & 253 & 2.07 & 23.1 & 42.4 & 159.6 & 2.7 & 6.8 \\
\hline max & 611 & 10.0 & 26.6 & 55.3 & 253.6 & 17.2 & 12.4 \\
\hline
\end{tabular}

Figures 1 and 2 show histograms of $\Delta \mathrm{CO}_{2}$ and ventilation rate, respectively. The boundaries for the categories used in the regression analysis were placed at the low points in these histograms.

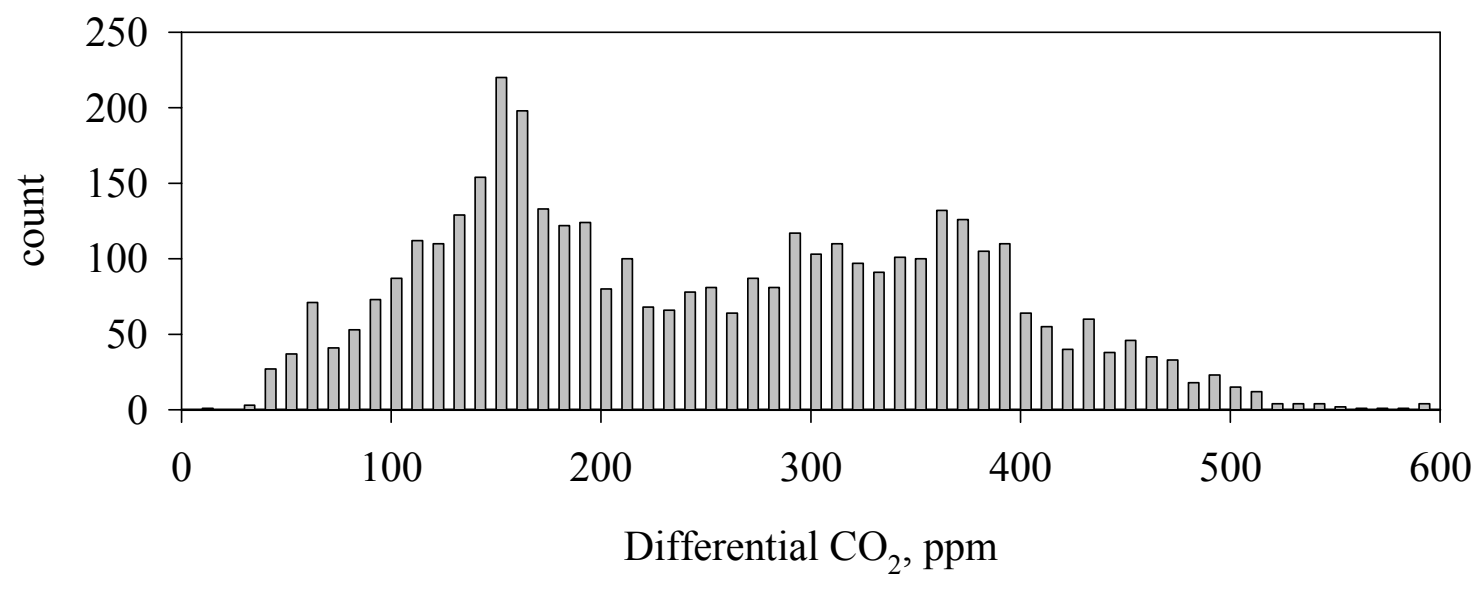

Figure 1: Histogram of differential $\mathrm{CO} 2$

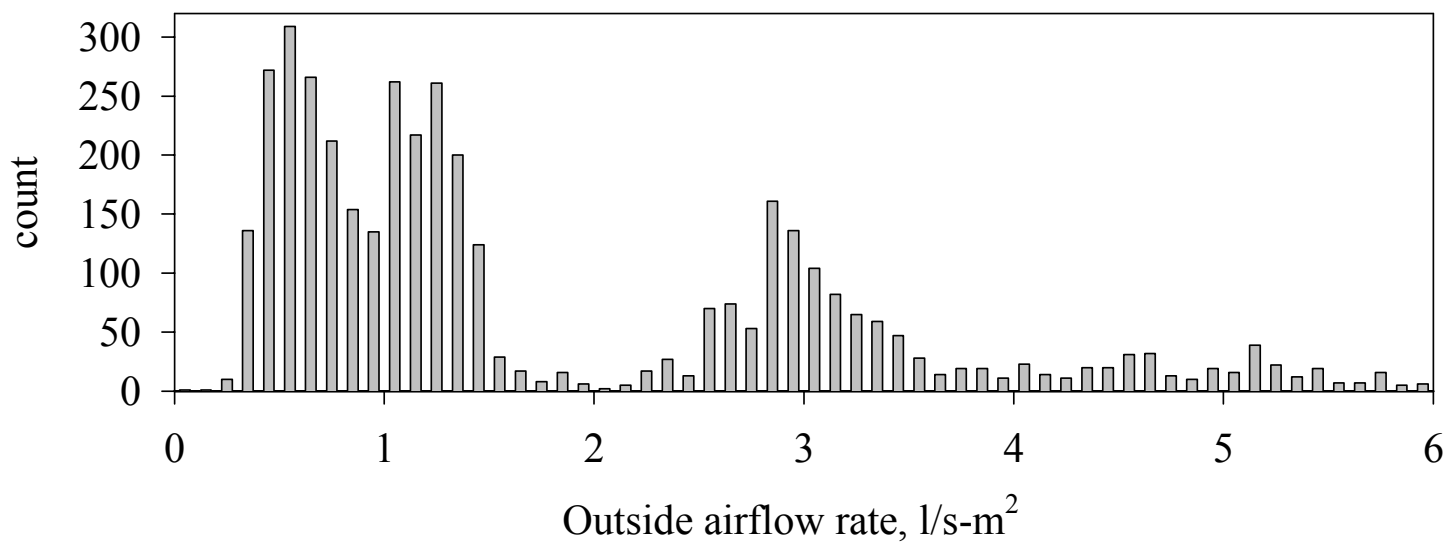


Figures 3 and 4 show the predicted association between talk time and the $\Delta \mathrm{CO}_{2}$ and ventilation categories. In both cases, the highest ventilation rate (lowest $\Delta \mathrm{CO}_{2}$ ) is the baseline. Vertical bars in these and all successive figures are standard errors. Boundaries for the $\Delta \mathrm{CO}_{2}$ categories are at 125,250 , and $325 \mathrm{ppm}$. The p-values for the category coefficients are shown on the figures. The boundaries for the ventilation categories are $0.91,2.03$, and $3.661 / \mathrm{s}-\mathrm{m} 2$.

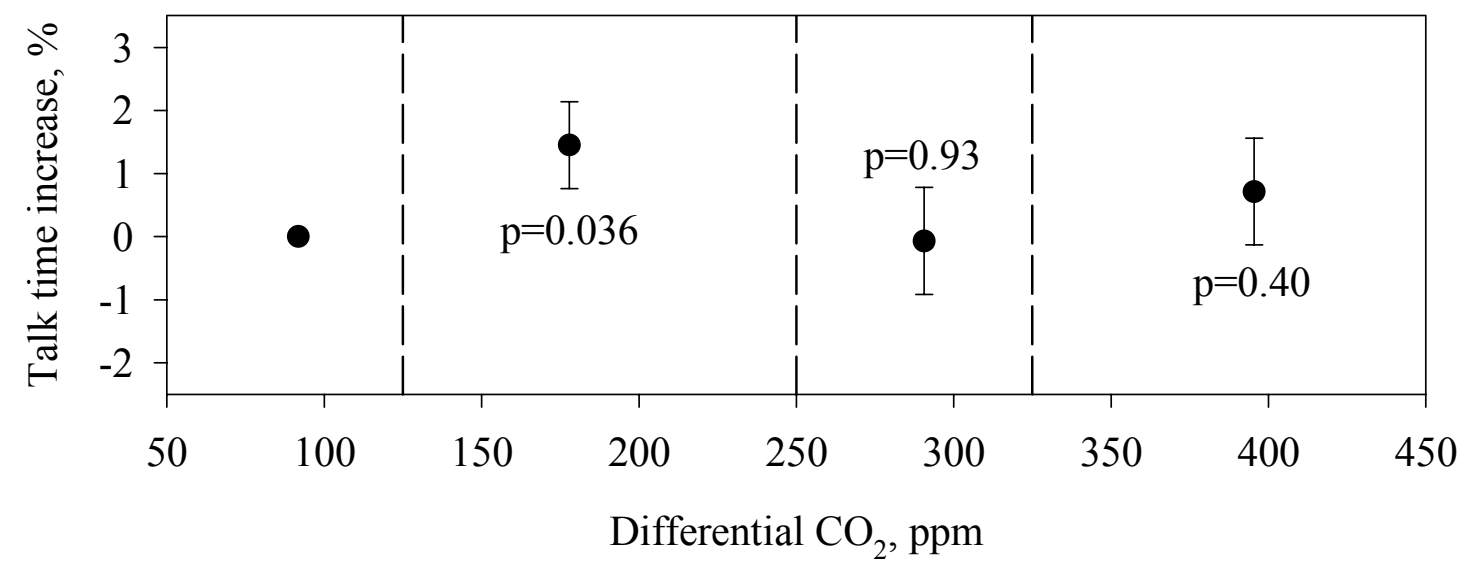

Figure 3: $\Delta \mathrm{CO}_{2}$ category coefficients for talk model.

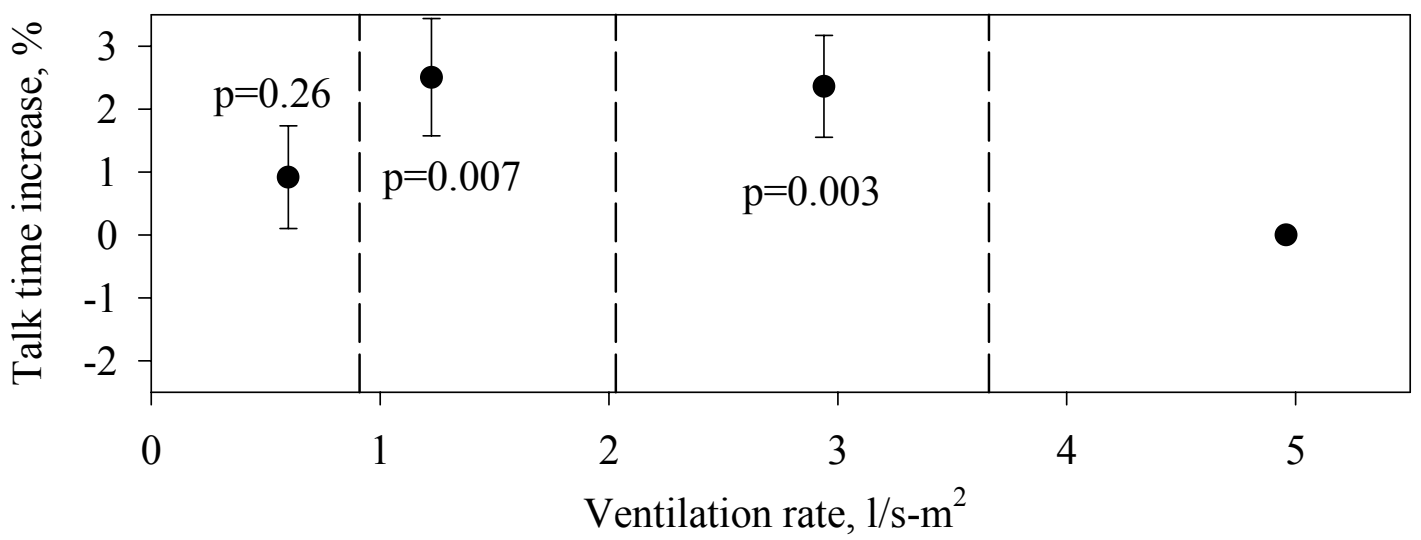

Figure 4: Ventilation category coefficients for talk model.

The talk time models predict that agents performed the talk task $3.9 \%$ and $4.3 \%$ slower $\left(\Delta \mathrm{CO}_{2}\right.$ and ventilation, respectively) after the software upgrade $(\mathrm{p}=0)$.

The models of wrap-up time did not show a statistically significant association between wrap-up time and $\Delta \mathrm{CO}_{2}$ or ventilation rate. Figures 5 and 6 show the predicted association between wrap up time and $\Delta \mathrm{CO}_{2}$ and ventilation rate. When we replaced the categorical $\Delta \mathrm{CO}_{2}$ terms with a linear term, the model predicted wrap-up times would be $4.4 \%$ slower at $\Delta \mathrm{CO}_{2}=600 \mathrm{ppm}$ than at $\Delta \mathrm{CO}_{2}=100 \mathrm{ppm}(\mathrm{p}=0.125)$. When we replaced the categorical ventilation rate term with a linear term, the model predicted that wrap-up times would be $3 \%$ longer at $0.5 \mathrm{l} / \mathrm{s}-\mathrm{m} 2$ than at 5 $1 / \mathrm{s}-\mathrm{m} 2(\mathrm{p}=0.095)$. 


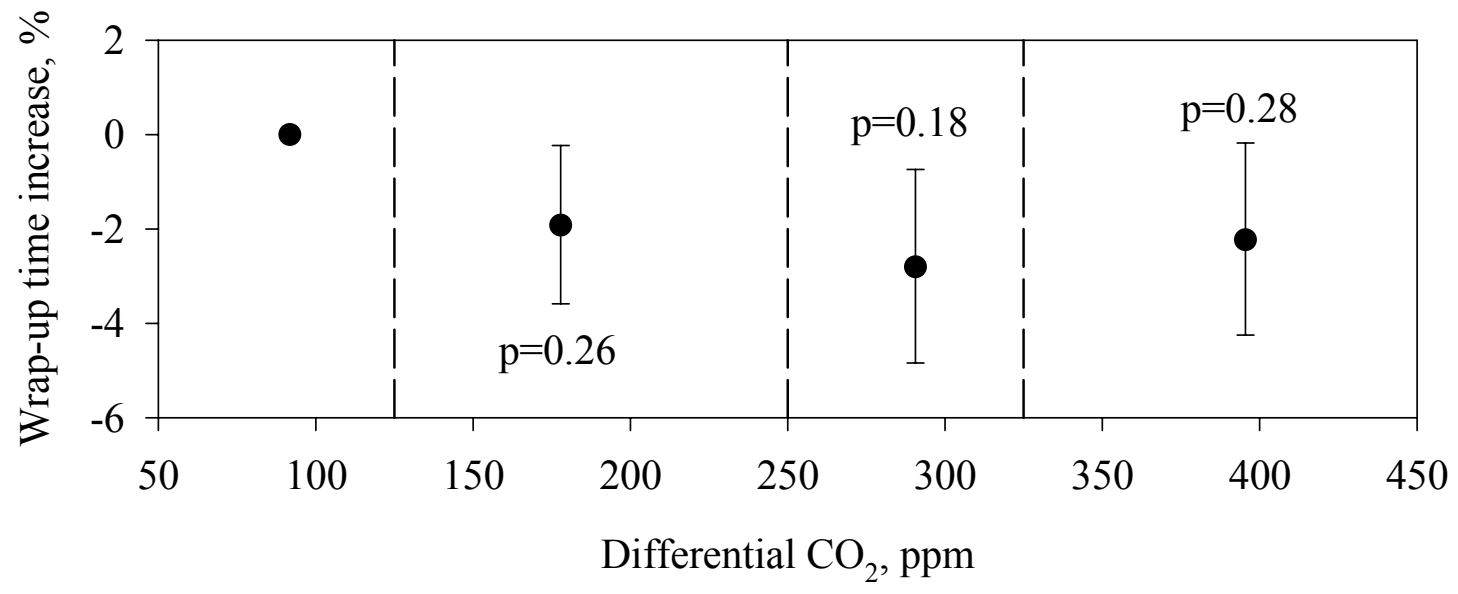

Figure 5: $\Delta \mathrm{CO}_{2}$ category coefficients for wrap-up model.

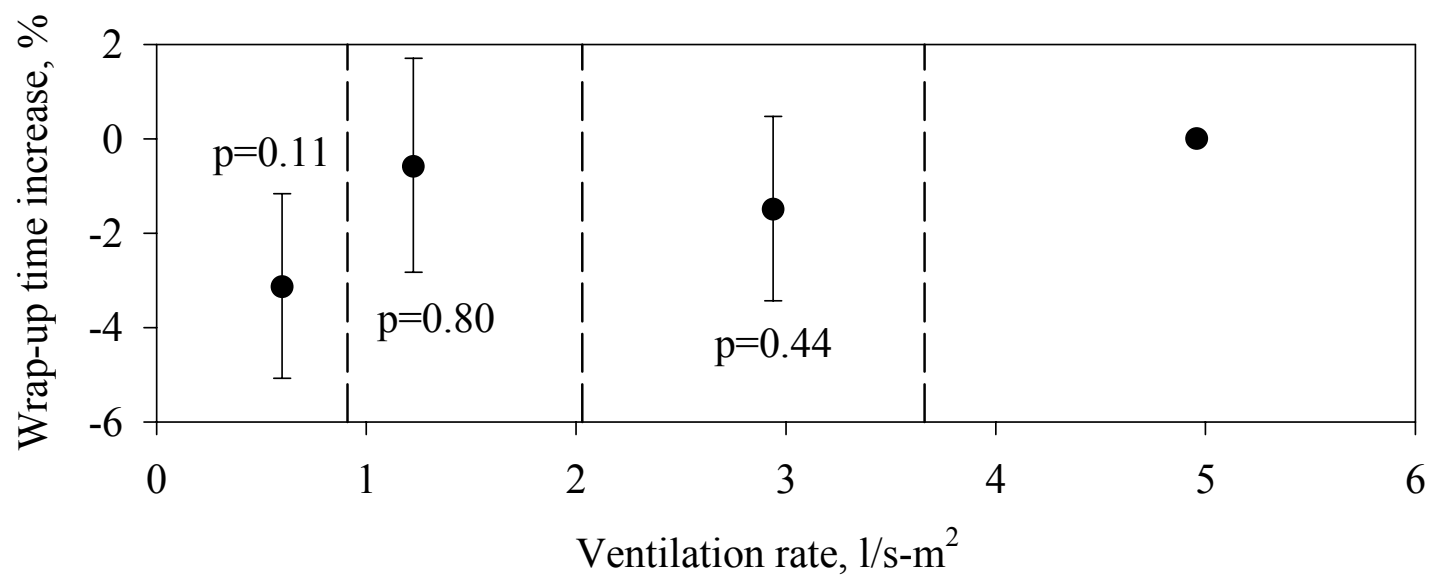

Figure 6: Ventilation category coefficients for wrap-up model.

The wrap-up time models showed an association between wrap-up time and temperature, NETS, and shift length. Figure 7 shows the temperature distribution to which the agents were exposed. Figure 8 shows the coefficients of the temperature categories for the wrap-up model containing $\Delta \mathrm{CO}_{2}$ categorical variables. The baseline is $23{ }^{\circ} \mathrm{C}$. The boundaries between the categories are $21.7,22.5,23.5,24.5$, and $25.4^{\circ} \mathrm{C}$. The model with ventilation rate categories also predicts lower performance at high temperature. 


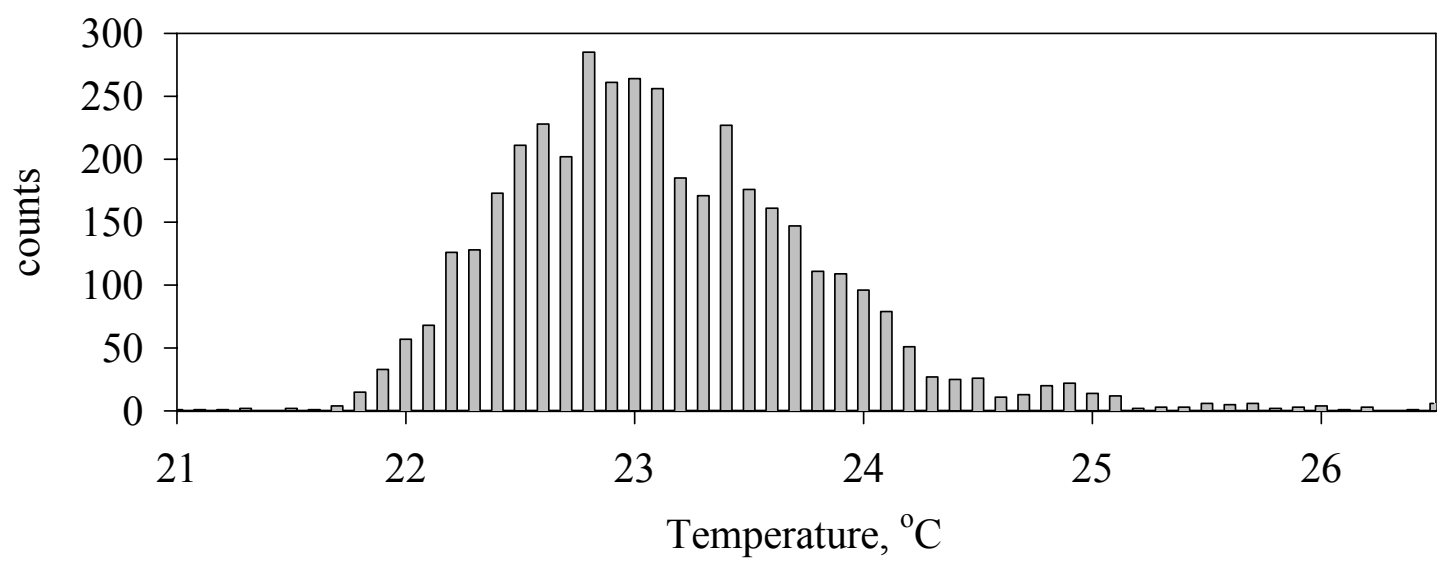

Figure 7: Temperature distribution.

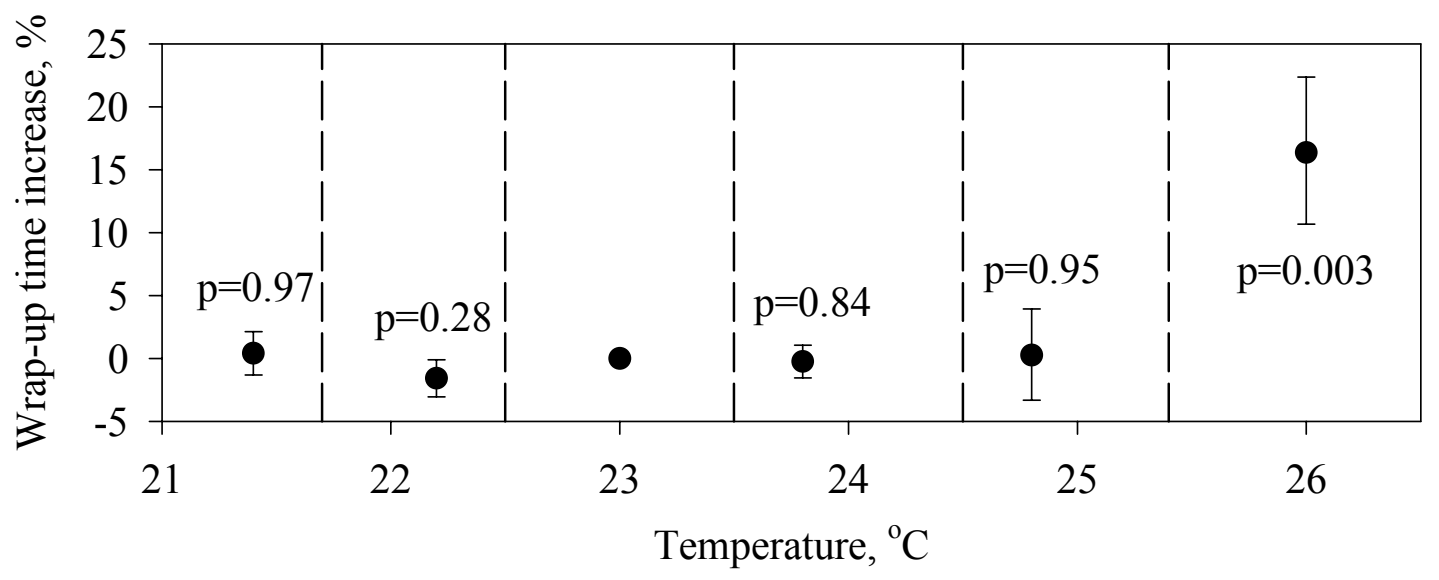

Figure 8: Temperature coefficients for wrap-up model with $\Delta \mathrm{CO}_{2}$.

All of the exposures above $25.4^{\circ} \mathrm{C}$ came from a single neighborhood located on the first floor of the south side of the building at the end of an extended wing. The neighborhood had an external exposure on three sides. Figure 9 shows a time series of the temperature in that neighborhood during some of the high-temperature periods. The time series shows abrupt changes in temperature that are characteristic of setpoint changes. With only one exception (July 20 at $10 \mathrm{pm}$ ), all of the abrupt increases occurred during the night and all of the abrupt decreases occurred during the day. The agents were allowed to adjust the setpoints on the thermostats located throughout the call center. These data suggest that the agents who worked at night in this neighborhood were "fighting" with the agents who worked during the day in this neighborhood over the temperature setting. 


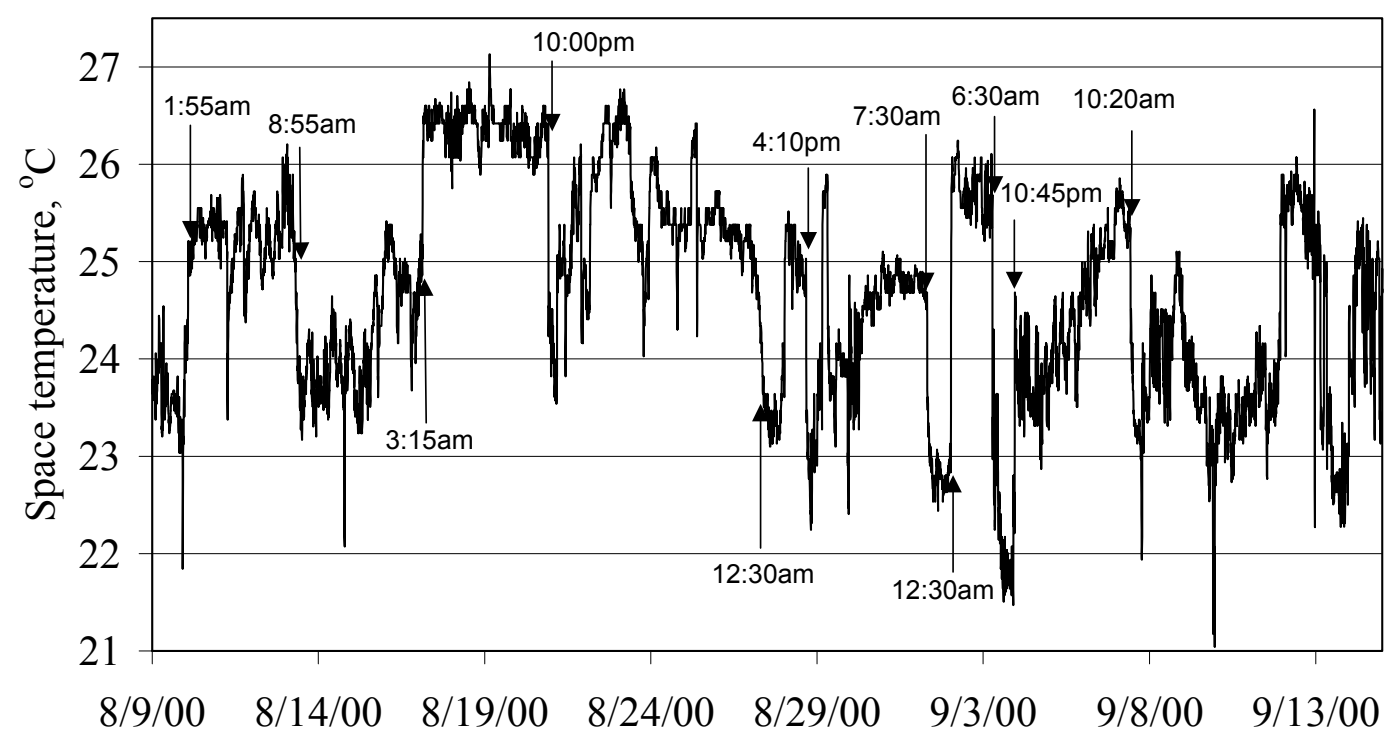

Figure 9: Temperature time series showing high exposures.

Figure 10 shows the coefficients of the NETS categories for the $\Delta \mathrm{CO}_{2}$ wrap-up model. The baseline is NETS $=0$, meaning no under-staffing or over-staffing. There is a clear trend showing that agents perform wrap-up fastest when NETS is positive (call center overstaffed). When the categorical terms were replaced with a linear term, the model predicted that wrap-up would decrease by $7.4 \%$ when NETS was increased from -7 to $13(\mathrm{p}=0.014)$.

Figure 11 shows the coefficients of the shift length categories for the $\Delta \mathrm{CO}_{2}$ wrap-up model. There is an increasing trend. When the categorical terms were replaced with a linear term the model predicted that wrap-up would be $10.7 \%$ slower during ten-hour shifts than during twohour shifts $(\mathrm{p}=0.069)$.

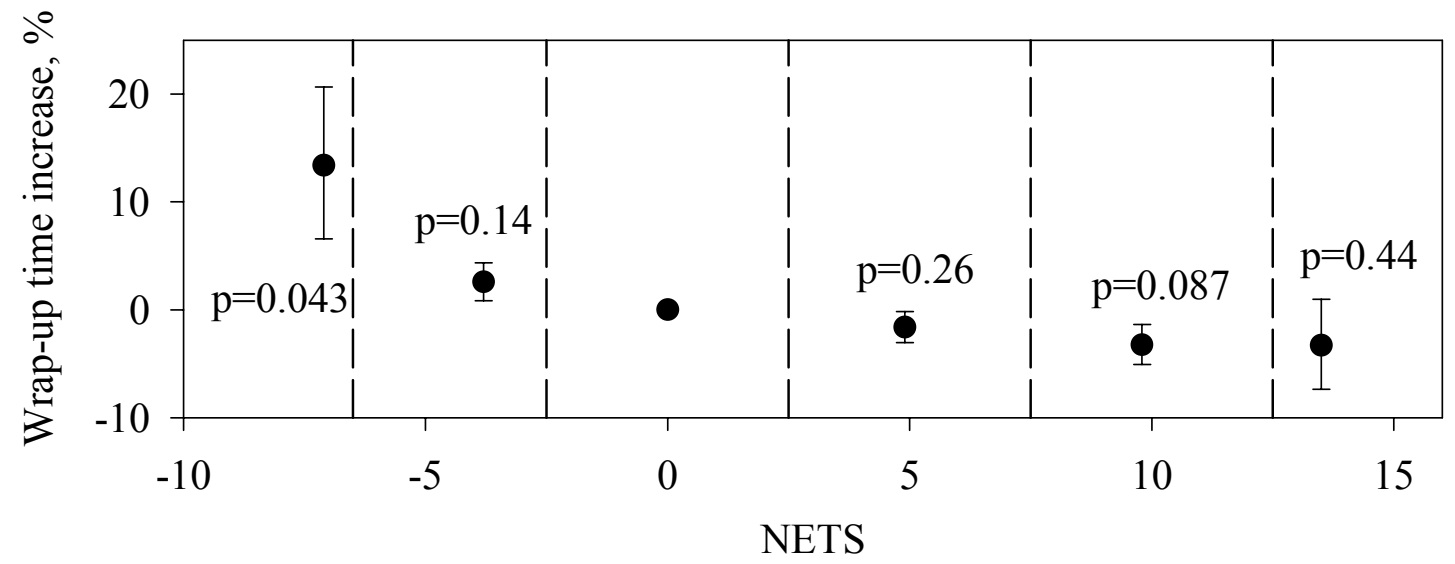

Figure 10: NETS coefficients for wrap-up model with $\Delta \mathrm{CO}_{2}$. 


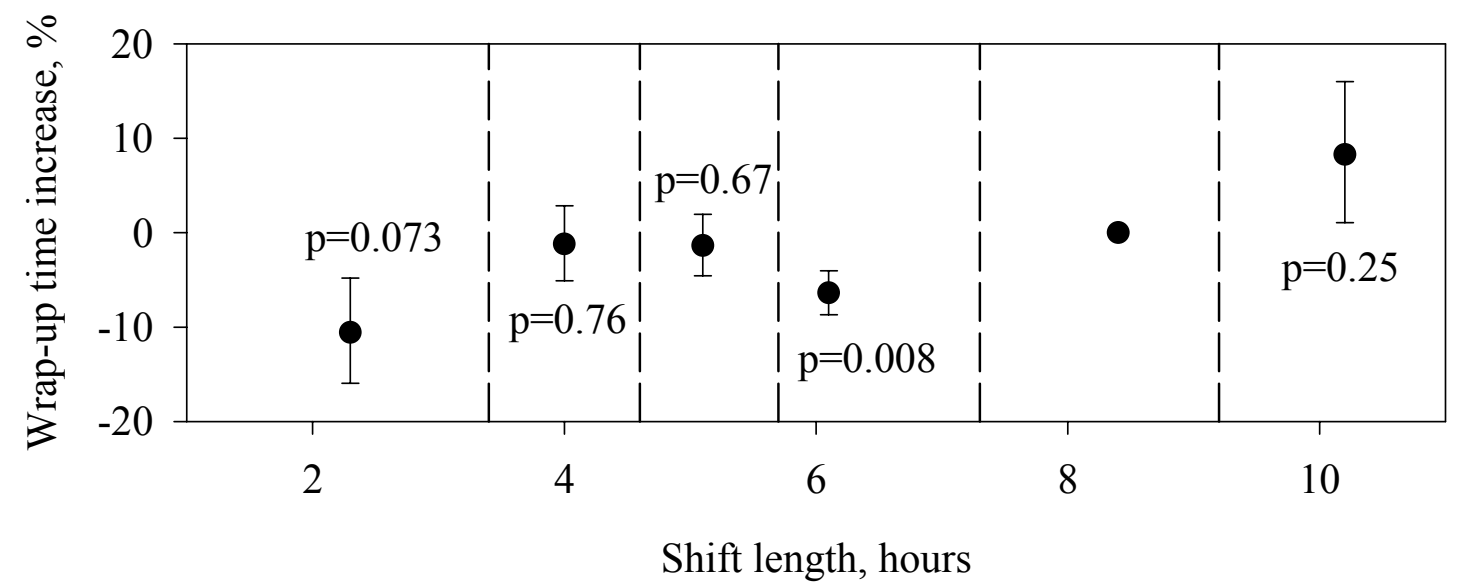

Figure 11: Shift length coefficients for wrap-up model with $\Delta \mathrm{CO}_{2}$.

The wrap-up model with $\Delta \mathrm{CO}_{2}$ categories predicts that wrap-up was $29.6 \%$ longer at maximum occupancy than when the call center was nearly empty but the term was not statistically significant $(\mathrm{p}=0.13)$. The same model predicted that wrap-up was $7.8 \%$ shorter after the software upgrade $(\mathrm{p}=0)$.

\section{Group Performance}

We fit several dozen regression models, using different definitions for the bin boundaries for number of calls, normalized nets, and $\Delta \mathrm{CO}_{2}$, and using different subsets of the data. Measures of model fit were very similar for all models that included the full set of explanatory variables, whatever the details of the model.

In every model that we tried, including Models A-C discussed below, the "nets" variables were found to be highly influential. For example, when nets was very negative---that is, when there were many more calls than the agents were able to handle---log(AHT) was elevated by more than $7 \%$ compared to the same day and time of day in different weeks. This effect is substantially larger than any expected effect of ventilation, so failure to accurately model the variation of $\log (\mathrm{AHT})$ with "nets" could potentially overshadow a ventilation effect. The fivecategory piecewise-linear relationship between $\log (\mathrm{AHT})$ and "nets" that we used in the models allows a more complicated relationship between nets and AHT than would an assumed linear or quadratic relationship across the whole range of "nets" values.

We also included half-hour lagged "nets" in the regressions. Lagged "nets" is the value of "nets" in the previous half-hour. This variable, which was found to be influential, may be important because some calls that terminated in a given half-hour were started in the previous one, and because lagged nets may help predict agent fatigue. Additionally, the mix of calls in a given half-hour period is affected by the wait times from the previous periods: some callers who abandoned calls in the previous period will call back. Although we also examined non-linear relationships between lagged "nets" and $\log (\mathrm{AHT})$, these models provided no advantage over linear models for this variable. In the models discussed below, we assumed $\log (\mathrm{AHT})$ to vary linearly with lagged "nets." 
We now discuss three specific models for $\log (\mathrm{AHT})$ in some detail. Each of these models includes: the time-of-week indicator variables; temperature $-23{ }^{\circ} \mathrm{C}$ and (temperature $-23{ }^{\circ} \mathrm{C}$ ) 2 ; number of agents on duty; five piecewise-linear "normalized nets" categories; and lagged "nets", allowing linear variation of $\log (\mathrm{AHT})$ with the "nets" value of one half hour previous. The three models differ only in their handling of $\Delta \mathrm{CO}_{2}$. Model $\mathrm{A}$ includes no $\Delta \mathrm{CO}_{2}$ variable. Model $\mathrm{B}$ includes three $\Delta \mathrm{CO}_{2}$ categorical variables, indicating whether $\Delta \mathrm{CO}_{2}$ for each half hour was: 0$150 \mathrm{ppm}, 150-300 \mathrm{ppm}$, or over $300 \mathrm{ppm}$. In Model C, the two lower $\Delta \mathrm{CO}_{2}$ categories within Model $\mathrm{B}$ have been split, thus, Model $\mathrm{C}$ has five $\Delta \mathrm{CO}_{2}$ categorical variables: 0-75 ppm, 75-150 ppm, 150-225 ppm, 225-300 ppm, or over 300 ppm. Table 2 identifies the variables used in each model and provides some of the regression coefficients and associated uncertainties.

Table 2: Regression coefficient estimates and standard errors for three statistical models of $\log (\mathrm{AHT})$ on the listed set of explanatory variables. Coefficient estimates for the 105 timeof-week effects, five "nets" categories, and five "nets" slopes are not shown, but are similar for all three models.

\begin{tabular}{|c|c|c|c|}
\hline Coefficient estimate [units] & Model A & Model B & Model C \\
\hline $\begin{array}{l}<\text { Time of week }> \\
{[\log (\text { AHT })]}\end{array}$ & $\begin{array}{l}\text { Included in } \\
\text { model }\end{array}$ & Included in model & Included in model \\
\hline $\begin{array}{l}<\text { five "nets" categories }> \\
{[\log (\text { AHT })]}\end{array}$ & $\begin{array}{l}\text { Included in } \\
\text { model }\end{array}$ & Included in model & Included in model \\
\hline $\begin{array}{l}<\text { five "nets"slopes }> \\
{[\log (\text { AHT }) / \text { nets }]}\end{array}$ & $\begin{array}{l}\text { Included in } \\
\text { model }\end{array}$ & Included in model & Included in model \\
\hline $\begin{array}{l}\text { Lagged "nets" } \\
{[\log (\text { AHT }) / \text { nets }]}\end{array}$ & $0.048+/-0.015$ & $0.053+/-0.015$ & $0.054+/-0.015$ \\
\hline $\begin{array}{l}\left(\operatorname{temp}-23^{\circ} \mathrm{C}\right) \\
{[\log (\mathrm{AHT}) / \text { degree } \mathrm{C}]}\end{array}$ & $-0.24+/-0.45$ & $-0.23+/-0.44$ & $-0.13+/-0.43$ \\
\hline $\begin{array}{l}\left(\operatorname{temp}-23^{\circ} \mathrm{C}\right)^{\wedge} 2 \\
{\left[\log (\mathrm{AHT}) /(\text { degree } \mathrm{C})^{\wedge} 2\right]}\end{array}$ & $0.007+/-0.027$ & $0.006+/-0.03$ & $0.004+/-0.029$ \\
\hline $\begin{array}{l}\text { Relative Humidity } \\
{[\log (\mathrm{AHT}) / \%]}\end{array}$ & $0.11+/-0.22$ & $0.11+/-0.22$ & $0.06+/-0.22$ \\
\hline $\begin{array}{l}\text { Agents on duty } \\
{[\log (\text { AHT }) / \text { agent }]}\end{array}$ & $0.0016+/-0.0004$ & $0.0017+/-0.0004$ & $0.0017+/-0.0004$ \\
\hline $\begin{array}{l}0<\Delta \mathrm{CO}_{2}<75 \\
{[\log (\mathrm{AHT})]}\end{array}$ & Not in model & $0.00+/-0.00$ & $0.00+/-0.00$ \\
\hline $\begin{array}{l}75<\Delta \mathrm{CO}_{2}<150 \\
{[\log (\mathrm{AHT})]}\end{array}$ & Not in model & Not in model & $0.036+/-0.010$ \\
\hline $\begin{array}{l}150<\Delta \mathrm{CO}_{2}<225 \\
{[\log (\mathrm{AHT})]}\end{array}$ & Not in model & $-0.002+/-0.004$ & $0.031+/-0.010$ \\
\hline $\begin{array}{l}225<\Delta \mathrm{CO}_{2}<300 \\
{[\log (\mathrm{AHT})]}\end{array}$ & Not in model & Not in model & $0.027+/-0.010$ \\
\hline $\begin{array}{l}300<\Delta \mathrm{CO}_{2} \\
{[\log (\mathrm{AHT})]}\end{array}$ & Not in model & $-0.009+/-0.006$ & $0.022+/-0.010$ \\
\hline $\begin{array}{l}{[\log (\mathrm{AHT})] \text { Residual standard }} \\
\text { error }\end{array}$ & 0.0446 & 0.0445 & 0.0442 \\
\hline
\end{tabular}


Figure 12 shows the residuals from Model A (which did not include $\Delta \mathrm{CO}_{2}$ ), plotted versus $\Delta \mathrm{CO}_{2}$. A lowess local regression fit is shown as a solid line (we used a smoother span of $1 / 5$, and 3 iterations). Only for low $\Delta \mathrm{CO}_{2}$ values is there any evidence that the residuals might vary with $\Delta \mathrm{CO}_{2}$; the model tends to predict longer handle times than were actually observed for very low $\Delta \mathrm{CO}_{2}$ concentrations. The right-hand portion of Fig. 3 shows a histogram of the residuals, with a normal distribution (mean 0 , standard deviation 0.0448 ) superimposed. The distribution of residuals is very close to normal, as we assume when we perform least-squares regressions.

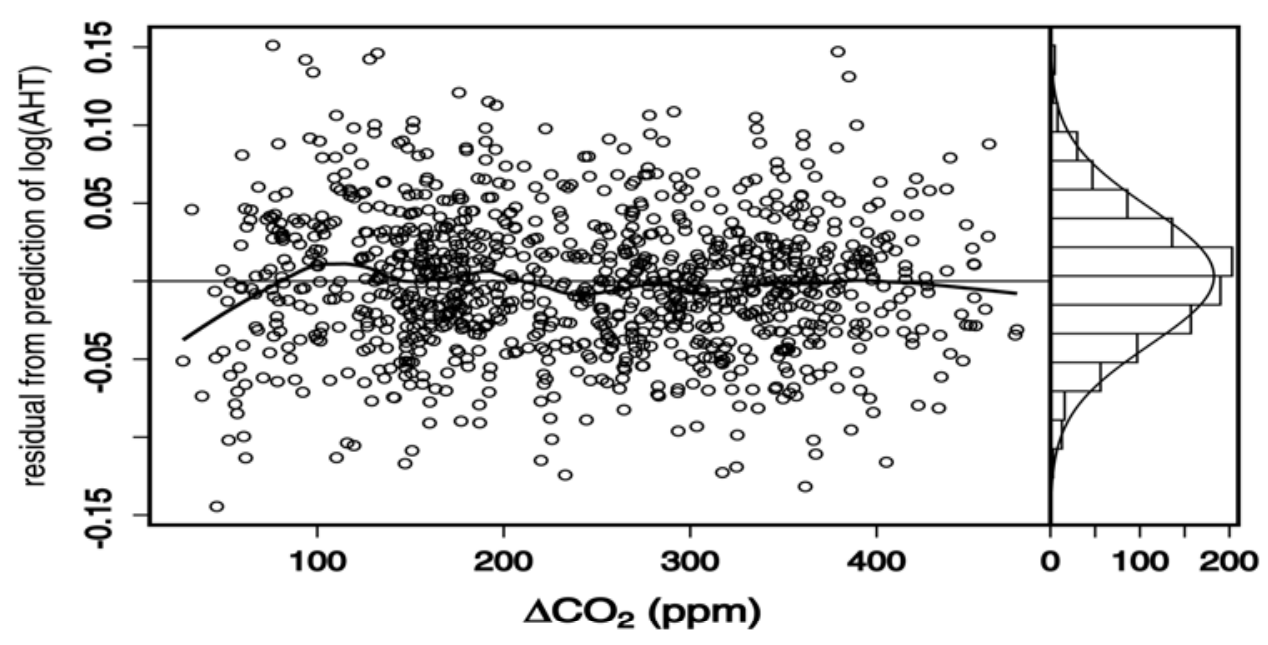

Figure 12: Residuals from regression model $A$, which does not include a carbon dioxide variable, versus indoor minus outdoor carbon dioxide concentration.

Figure 13 shows the estimated model coefficients associated with each $\Delta \mathrm{CO}_{2}$ bin, for Models $\mathrm{B}$ (lower plot) and $\mathrm{C}$ (upper plot). For each bin, the horizontal bar shows the range of $\Delta \mathrm{CO}_{2}$ spanned by the bin, and the vertical error bar covers plus or minus one standard error. In each case, the lowest bin is defined to have no effect, a coefficient of 0.00 .
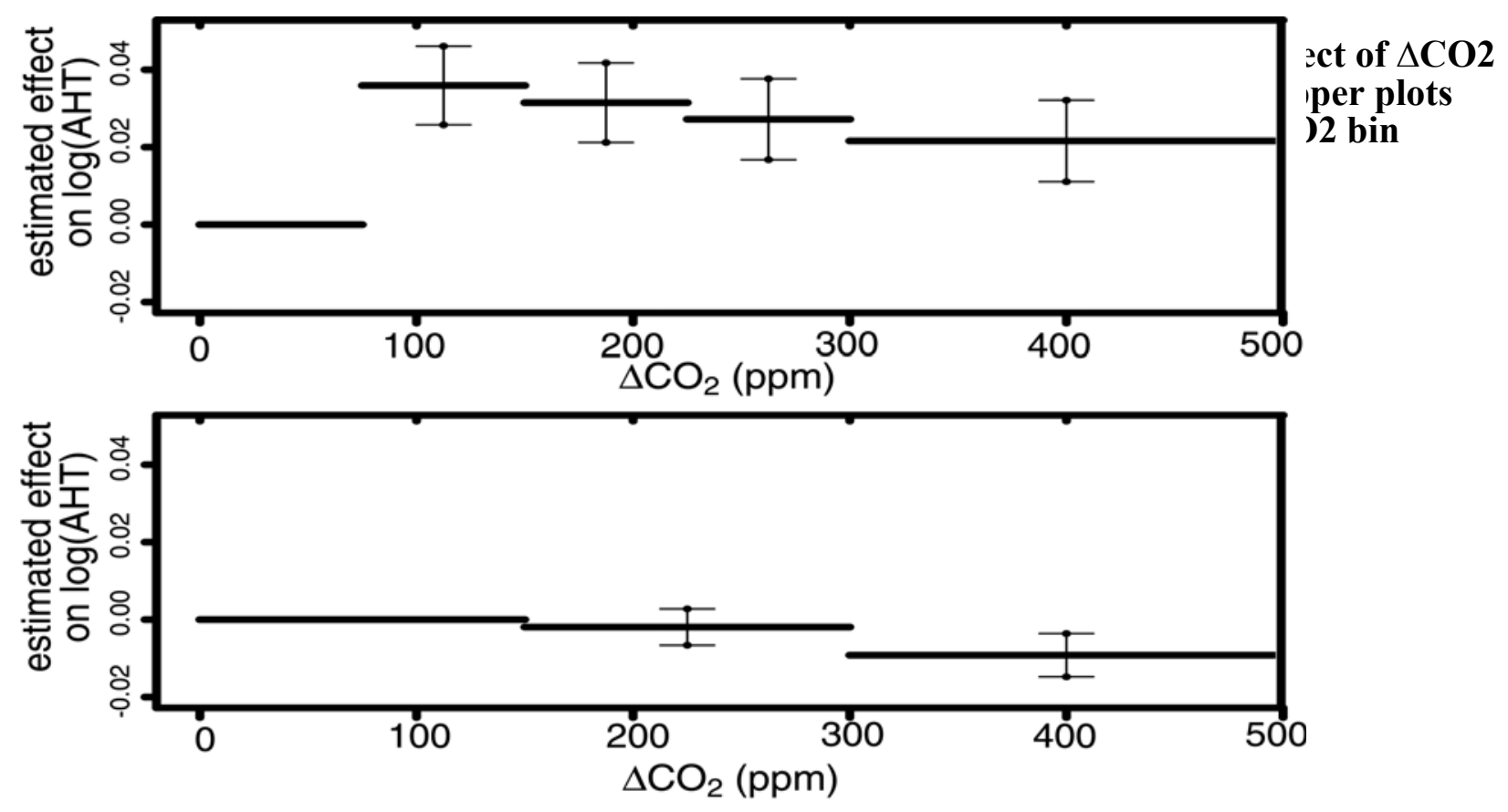
In the model with only three $\Delta \mathrm{CO}_{2}$ bins (Model B) there is no evidence that lower $\Delta \mathrm{CO}_{2}$ is associated with lower (faster) AHT---indeed, the relationship points the other direction: the estimate for the high- $\Delta \mathrm{CO}_{2}$ bin is about $1 \%$ faster than that for the lowest bin (an effect of -0.009 on $\log ($ AHT $)$ corresponds to a factor of $\exp (-0.009)=0.991$ on AHT, which is very close to a $1 \%$ speed-up). However, this estimate is not very precise, with an uncertainty (one standard error) of approximately \pm 0.6 percentage points.

In contrast, the results from Model $\mathrm{C}$ suggest that very low $\Delta \mathrm{CO}_{2}$ concentrations are associated with lower AHT (faster work) than are higher concentrations. All of the estimated coefficients for $\Delta \mathrm{CO}_{2}$ concentrations over $75 \mathrm{ppm}$ are around 0.025 to 0.035 , corresponding to handle times that are $2.5 \%$ to $3.5 \%$ slower than at the lowest $\Delta \mathrm{CO}_{2}$. Moreover, these effects are all highly statistically significant ( $\mathrm{p}<0.05$ for all bin coefficients). However, as we discuss below, we think the statistical uncertainties are understated and that the relationship between AHT and $\Delta \mathrm{CO}_{2}$ is far from conclusive.

Overall, neither the Model B nor Model C results show evidence that AHT increases with $\Delta \mathrm{CO}_{2}$ over most of its range. A dependence of $\log (\mathrm{AHT})$ on $\Delta \mathrm{CO}_{2}$ is apparent only for $\Delta \mathrm{CO}_{2}$ concentrations below about $150 \mathrm{ppm}$ : $\log (\mathrm{AHT})$ is somewhat lower for $\Delta \mathrm{CO}_{2}$ concentrations in the $0-75 \mathrm{ppm}$ range than in the $75-150 \mathrm{ppm}$ range, after adjusting for all of the other explanatory variables. When the $0-150 \mathrm{ppm} \Delta \mathrm{CO}_{2}$ category is split into two categories, as in Model $\mathrm{C}$, the 0 $75 \Delta \mathrm{CO}_{2}$ category has the lowest (fastest) values of $\log (\mathrm{AHT})$, after adjusting for the other explanatory variables. But when the $\Delta \mathrm{CO}_{2}$ data from 0-150 ppm are combined into a single bin, as in Model B, the overall average AHT in this bin is about the same as in the other bins.

In another model, we treated $\Delta \mathrm{CO}_{2}$ as a continuous variable throughout the entire concentration range and found no statistically significant or strong relationship between $\Delta \mathrm{CO}_{2}$ and AHT. These findings were essentially unchanged, when data collected after day 57 were excluded from the analyses in order to eliminate any possible effects of the change in software on day 58.

The analyses based on $\Delta \mathrm{CO}_{2}$, which is a proxy for ventilation per person, assume that effects on AHT would be caused by pollutants with indoor concentrations approximately proportional to the number of people. However, the building itself can also be a source of pollutants, independent of the number of people in it: walls or carpeting may emit volatile organic compounds, for example. If the building is the source of pollutants that affect performance, then it is total ventilation rate, not ventilation per person, should predict variation in AHT. We investigated this possibility by fitting Models like A-C, but using ventilation rate categories rather than $\Delta \mathrm{CO}_{2}$ categories. There is no evidence for a dependency of AHT on ventilation rate; in fact, even for the highest values of ventilation rate there is no evidence for reduced handle time compared to lower ventilation rate values. To the extent that there is an apparent ventilation-related effect in this study, it is due to ventilation rate per person (as indicated by $\Delta \mathrm{CO}_{2}$ ) rather than ventilation per unit indoor air volume.

\section{DISCUSSION}


We expected, but did not find, a dose-response relationship between ventilation and work performance. Instead the individual performance analysis showed that performance at low and high ventilation rates was statistically the same, that performance at intermediate ventilation rates was worse by about $2 \%$, at that the increased talk time (decreased work speed) was statistically significant. We tried a number of different models, including models containing the air quality proxies multiplied by shift length (time of exposure). The pattern described above showed up in most of these models. Qualitatively, the group performance analysis showed a similar relationship, with the predicted performance worst at intermediate ventilation rates. These findings are similar to the findings of Jaakola and Miettinen (1995). In that study, the risk of SBS symptoms increased at ventilation rates above $25 \mathrm{l} / \mathrm{s} /$ person in comparison to $15-25$ $1 / \mathrm{s} /$ person. An increased risk was observed for all symptoms, and was statistically significant for eye symptoms, mucosal irritation, and allergic reaction.

We found that what evidence there was of an association between ventilation and performance showed up in the talk task and not in the wrap-up task. We expected that productivity loss would be more likely during wrap-up because agents are free to work at their own pace; they are not constrained by their interaction with a client. It is possible that our non-intuitive findings are the result of an unidentified confounding factor.

There is recent evidence that pollutants trapped in filters may play a role in the relationship between work performance in call centers and indoor air quality (Wargocki et al., 2003). Alm et al. (2000) showed that the pollutant concentration released from a dirty filter increased with the velocity of air passing through the filter. We found that the average velocity of air passing through the filters increased as the ventilation rate increased. The average filter face velocities corresponding to the ventilation categories (from lowest to highest) were 1.77, 1.99, 1.86, and $2.00 \mathrm{~m} / \mathrm{s}$. The face velocities for the $\Delta \mathrm{CO}_{2}$ categories (from lowest to highest $\Delta \mathrm{CO}_{2}$ ) were 2.04, $1.97,1.86$, and $1.73 \mathrm{~m} / \mathrm{s}$. The variable supply flow rates in our study may have played a role in the findings regarding ventilation since the filters may have been emitting more pollutants at the higher face velocities, which corresponded to higher ventilation rates.

We found that agents were $16 \%$ slower at wrap-up when the temperature was greater than 25.4 ${ }^{\circ} \mathrm{C}$. This was the largest effect with a p-value less than $5 \%$. Temperatures greater than $25.4{ }^{\circ} \mathrm{C}$ occurred on only seven days, six of them in a nine-day period starting at day 21 . All of them occurred in the same neighborhood. Observation of the temperature time series in that neighborhood indicates that the daytime workers and the nighttime workers were fighting over the temperature setpoint. The nighttime workers wanted the temperature higher than the daytime workers. This neighborhood is located in a southern extension of the call center with three exposed walls surrounding it, so low radiant temperatures may have contributed to the need for a higher air temperature. Sometimes the nighttime workers would raise the setpoint very high and the daytime workers would not lower it for two or three days. This caused the high-temperature exposure that was correlated with slower task performance. Some models we tried showed a similar increase in wrap-up times at low temperatures, but the low-temperature terms were never statistically significant.

When the call center was understaffed agents performed wrap-up slower. This relationship was strong in both the individual performance analysis and the group performance analysis. The call 
center director predicted this effect prior to our analysis. The hypothesis is that when the call center is understaffed agents never get to rest between calls. They make up for the missing rest by working slower during wrap-up. This finding is contrary to the finding of Wargocki et al. (2003), who found that call center operators worked faster when the call center volume increased while the number of agents remained fixed.

\section{CONCLUSION AND IMPLICATIONS}

1. There is some evidence that ventilation rates less than $100 \%$ outdoor air were associated with lower work performance, but the results are not conclusive.

2. Agents worked slower at high temperature $(>25.4 \mathrm{C})$.

3. Agents worked slower when the call center is understaffed.

4. There is some evidence that agents worked slower when they work longer shifts.

\section{ACKNOWLEDGEMENTS}

This work was supported by the Center for the Built Environment at U.C. Berkeley and by the Assistant Secretary for Energy Efficiency and Renewable Energy, Building Technology Program, of the U.S. Department of Energy (DOE) under contract No. DE-AC03-76SF00098.

\section{REFERENCES}

Alm, O, Clausen, G, and Fanger, P O. 2000. Exposure-response relationships for emissions from used ventilation filters, Proceedings of Healthy Buildings 2000, Vol 2, pp 245-250. Espoo: Healthy Buildings 2000.

Bakó-Biró, Z., P. Wargocki, C. Weschler, P. O. Fanger, 2002, "Personal computers pollute indoor air: effects on perceived air quality, SBS symptoms and productivity in offices," Proceedings of Indoor Air 2002, 2, 249-254.

Box GEP, Jenkins GM, Reinsel G, 1994. Time Series Analysis, New Jersey: Prentice Hall.

Drees, K., J. Wenger, and G. Janu, 1992, "Ventilation Air Flow Measurement for ASHRAE Standard 62-1989," ASHRAE Journal, 34(10), 40-45.

Federspiel, C. C., G. Liu, M. Lahiff, D. Faulkner, D. Dibartolomeo, W. J. Fisk, P. N. Price, D. Sullivan, 2002, "Worker Performance and Ventilation: Analyses of Individual Data for CallCenter Workers," Proceedings of Indoor Air 2002, Vol. 1, 796-801, Indoor Air 2002, Inc., Santa Cruz, CA.

Fisk, WJ, Price, PN, Faulkner, D, Sullivan DP, Dibartolomeo, DL, Federspiel, CC, Liu, G, and M Lahiff, M. (2002) Worker performance and ventilation: analyses of time-series data for a group of call-center workers. Proceedings of Indoor Air 2002, vol. 1, pp. 790-795, Indoor Air 2002, Inc., Santa Cruz, CA.

Gelman A, Carlin JB, Stern HS, and Rubin DB, 1995. Bayesian Data Analysis. New York: Chapman and Hall. 
Jaakkola, J. J.K., O. S. Miettinen, and K. Komulainen, 1990, The Effect of Air Recirculation on Symptoms and Environmental Complaints in office workers. A double-blind, four period crossover study. Proceedings of Indoor Air '90, 1, 281-286.

Jaakkola, J. J. K., O. P. Heinonen, and O. Seppanen. 1991. Mechanical ventilation in office buildings and the sick building syndrome. A experimental and epidemiological study. Indoor Air. 2. 111-121.

Jaakkola, J. J.K., O. S. Miettinen, 1995, "Ventilation rate in office buildings and sick building syndrome," Occupational and Environmental Medicine, 52, 709-714.

Kroner WM, Stark-Martin JA, Willemain T (1992) Using advanced office technology to increase productivity: the impact of environmentally responsive work stations (ERWs)on productivity and worker attitude. Troy, NY: Rensselaer Polytechnic Institute, Center for Architectural Research

Lagercrantz, L., M. Wistrand, U. Willén, P. Wargocki, T. Witterseh, and J. Sundell, 2000, "Negative impact of air pollution on productivity: previous Danish findings repeated in new Swedish test room, Proceedings of Healthy Buildings 2000, Helsinki, 1, 653-658.

Mendell, M. J., 1993, Non-specific symptoms in office workers: a review and summary of the epidemiologic literature. Indoor Air, 3, 227-236

Menzies et al., 1993, The Effect of Varying Levels of Outdoor-Air Supply on the Symptoms of Sick Building Syndrome, The New England Journal of Medicine, 328(12), 821-827.

Milton D, Glencross P, Walters M. 2000. Risk of sick leave associated with outdoor airsupply rate, humidification, and occupant complaints. Indoor Air $10(4): 212-221$.

Myatt, T. A., J. Staudenmayer, K. Adams, M. Walters, M. Wand, S. Rudnick, and D. K. Milton, 2002, "An intervention study of outdoor air supply rates and sick leave among office workers," Proceedings of Indoor Air 2002, 1, 778-783.

Myhrvold AN, Olsen E, Lauridsen O. 1996. Indoor environment in schools - pupils health and performance in regard to $\mathrm{CO}_{2}$ concentrations. Proc. Indoor Air 1996, The $7^{\text {th }}$ International Conference on Indoor Air Quality and Climate. 4: 369-374. SEEC Ishibashi Inc., Japan.

Niemela, R., M. Hannula, S. Rautio, K. Reijula, and J. Railio, 2002, "The effect of air temperature on labor productivity in call centers: a case study," Energy and Buildings, 34, 759-764.

Nunes F, Menzies R, Tamblyn RM, et al. 1993. The effect of varying level of outside air supply on neurobehavioral performance function during a study of sick building syndrome. Proceedings of the 6th International Conference on Indoor Air Quality and Climate - Indoor Air 1993, Vol. 1, pp. 53-58. Indoor Air 1993, Helsinki.

Seppanen OA, Fisk WJ, Mendell MJ. 1999. Association of ventilation rates and $\mathrm{CO}_{2-}$. concentrations with health and other responses in commercial and institutional buildings. Indoor Air 9: 226-252.

Seppanen O. and Fisk WJ 2002, Association of ventilation system type with SBS symptoms in office workers. Indoor Air 12(2): 98-112. 
Seppanen O, Fisk WJ, 2003, A conceptual model to estimate cost effectiveness of the indoor environment improvements. Proceedings of Healthy Buildings 2003, December 7-11, 2003, Singapore.

Tham, K. W., H. C. Willem, S. C. Sekhar, D. P. Wyon, P. Wargocki, and P. O. Fanger, 2003, "Temperature and ventilation effects on the work performance of office workers (study of a call center in the tropics)," Proceedings of Healthy Buildings 2003, Singapore.

Wargocki P, Wyon DP, Sundell J, Clausen G, and Fanger PO, 2000, The effects of outdoor air supply rate in an office on perceived air quality, sick building syndrome (SBS) symptoms, and productivity. Indoor Air 10(4): 222-236

Wargocki, P., D. P. Wyon, and P. O. Fanger, 2003, "Call-centre operator performance with new and used filters at two outdoor air supply rates," Proceedings of Healthy Buildings 2003, Singapore.

Wyon, D. P., 1992, Sick Buildings and the Experimental Approach, Environmental Technology, $13,313-322$.

Wyon DP. 1993. Healthy buildings and their impact on productivity. Proc. Indoor Air'93, the 6th International Conference on Indoor Air Quality and Climate. 6: 3-13. Helsinki. Indoor Air 93.

Wyon DP. 1996a. Indoor environmental effects on productivity. Proc. IAQ'96 "Paths to Better Building Environments". pp 5-15, ASHRAE, Atlanta.

Wyon DP. 1996b. Individual microclimate control: required range, probable benefits, and current feasibility. Proc. of Indoor Air 96. 1:1067-1072. Tokyo. Institute of Public Health. 